East African Medical Journal Vol. 77 No. 3 March 2000

SEX DETERMINATION FROM FEMORAL HEAD DIAMETERS IN BLACK MALAWIANS

P.S. Igbigbi, MBBS, MSc and B.C. Msamati, MD, PhD, Department of Anatomy, College of Medicine, University of Malawi, Private Bag 360, Chichiri, Blantyre 3, Malawi

Request for reprints to: Dr. P S Igbigbi, Department of Anatomy, College of Medicine, Private Bag 360 Chichiri, Blantyre 3 Malawi

\title{
SEX DETERMINATION FROM FEMORAL HEAD DIAMETERS IN BLACK MALAWIANS
}

\author{
P.S. IGBIGBI and B.C. MSAMATI
}

\begin{abstract}
Objectives: To determine the sex of black Malawians from femoral head diameters. Design: A retrospective study on patients investigated in three $\mathrm{x}$-ray departments. Setting: Radiographs were collected from the archives of Queen Elizabeth Central, Chikwawa and Balaka hospitals.

Subject: X-ray films of 496 pelves of adult black patients aged 18-70 years were studied.

Main outcome measure: Femoral diameters were used to determine sex using the identification (IP) and demarking (DP) points.

Results: The mean diameter of male femoral heads was significantly greater $(P=0.001)$ than in females and the IP was significantly higher $(P=0.001)$ in males than in females. The IP of Malawian males was comparable to southwestern Nigerian males. More female bones were identified because the mean head diameter of male femurs fell within the range of diameters that fail to identify sex. The DP identified sex of a lower percentage of femurs when compared to the IP. However, both parameters also identified sex of a lower percentage of femurs when compared to those of Nigerians.

Conclusion: The femoral head diameters determined sex in adult black Malawians using the IP and DP points. In medico-legal cases where sophisticated methods of sex determination is lacking, these simple methods should be recommended especially in developing countries.
\end{abstract}

\section{INTRODUCTION}

Since human beings differ in size from each other between races, their morphological proportions would affect metric assessment of sex. For this reason different standards exist for identification of skeletal tissues like bones in different populations. For example, statistical analysis of femoral head diameters of different racial groups has been shown to vary a great deal(1). Sex determination from an available skeleton is of great forensic importance and it is also a useful anthropological data. Krogman(2) in 1946 showed that not more than $95 \%$ accuracy can be achieved even when all the bones of the human body are present. This makes the identification of sex from a single bone very difficult. Male bones are, however, generally longer, thicker and heavier, with more prominent areas of muscle attachment than those of females. These features are nevertheless subjective hence the need for measurable parameters that are expressed in appropriate scientific methods(3). Using the visual method alone, it was shown in two separate studies by Krogman(2) and Stewart(4) that sex could be assigned to not more than $13 \%(2)$ and $23 \%$ (4) of cases, respectively.
Several studies have been carried out to determine sex from measurements of femoral heads by many workers $(1,3,5-8)$. These authors did not report uniform values for all the races studied from different countries. This is because the measurements might have been affected by racial variations necessitated by diet, heredity, climate and other geographical factors(9). Current studies on sex determination tend to use discriminant function analysis using various bones like the patella, pubis and lateral radiographic cephalometry, respectively(9-11). Steyn and Iscan(12) used this method to determine sex from the femur and tibia in a South African white population (12). It has been shown, however, that the accuracy of these methods range from $83.3 \%$ in patella measurements to $100 \%$ in lateral radiographic cephalometry. It must be noted that these methods are more cumbersome and require more sophisticated equipment. Nonetheless, the simple methods by Jit and Singh(13), of identification (IP) and demarking points (DP) for sex determination are less cumbersome, require less measurements and appear to give $100 \%$ accuracy consistently.

Forensic anthropologists are a rarity in Africa. Most of the time anatomists are called upon in medico-legal 
cases, to determine the stature, sex and age of the skeletal remains of the deceased. It is therefore important to develop standards for skeletal identification for given populations. Few studies have been reported in blacks in Africa on the determination of sex from measurements of femoral heads, and these were mainly from Nigeria $(3,8,14)$. Literature on the subject is lacking and has not been reported previously in Malawi. In an attempt to provide baseline data for Malawians, the present study was carried out in adult subjects and it is hoped that this report would be useful in medico-legal cases in future.

\section{MATERIALS AND METHODS}

A total of $516 \mathrm{x}$-ray films of adult pelvis were collected from the archives of Queen Elizabeth Central Hospital (QECH) in Blantyre, Chikwawa District Hospital and Balaka Hospital. The radiographs used were 496 . Twenty did not fulfill the following criteria and were excluded from the study. The films selected showed the pelvis and hip joints, intact Shenton's lines, no fracture at the femoral necks, no pathological disorders, intact cortices at femoral heads and were of known sexes. Two hundred and sixty radiographs (520 femurs) were of male and 236 (472 femurs) were of female subjects aged 18 - 70 years. The films were taken at a routine object-film distance of $5 \mathrm{~cm}$ and focalfilm distance of $92 \mathrm{~cm}$ in the anterior-posterior view with the two big toes touching on their medial aspects.

The 1972 method of Singh and Singh(1) was used for measurements of the vertical and transverse diameters of the femoral heads (Figure 1), and a magnification correction factor of $2.86 \%$ was applied to the measurement(15). The results were statistically analysed using SAS statistical package for windows version 6.08 and the T-tests were employed to find differences between the sexes and the values of the right and left femoral head diameters. Identification and demarking points were determined for the different parameters using the method of Jit and Singh(13).

\section{Figure 1}

Sample radiograph showing how the vertical and transverse diameters of the femoral head were measured
Identification points (IP) are levels of femoral head diameters above which values are those of male bones and below which are female bones. The male identification point is therefore the maximum value of the range of diameters of the head of the female femur, while the identification point for the female is the minimum value of the range of values for the male (Figure 2).

\section{Figure 2}

Bar chart showing the ranges of head diameters of male and female femurs

(RVD-Right vertical diameter; LVD-Left vertical diameter; RTD Right tranverse diameter; LTD - Left tranverse diameter; IP Identification point; DP - Demarking point; m-Mean diameter for each group inside the box)

Note: Dotted and hatched areas respectively represent the range of diameter for which identification point (IP) and demarking point (DP) could identify the sex of femur

Demarking points (DP) are defined by the mean of femoral head diameters of the opposite sex plus (male) or minus (female) 3 times its standard deviation (Figure 2). Identification points are not as accurate when data are obtained from different locations within the same geographical area(3). In medico-legal cases, where $100 \%$ accuracy of identification of skeletal remains is required, the use of demarking points is preferable. Identification points, however, identify more bones than demarking points but with less accuracy.

\section{RESULTS}

Table 1 shows the measurements of the vertical and transverse femoral heads of the left and right femurs in males and females. The vertical and transverse diameters of the femoral heads of males were significantly greater than the corresponding diameters for females $(\mathrm{P}=0.001$, Table 1). Similarly, the vertical and transverse diameters of the femoral heads of males on the left side were significantly greater than the corresponding diameters of the femoral head of the female left femur $(\mathrm{P}=0.001)$. The mean vertical and transverse diameters of the femoral head for males were $48.30 \mathrm{~mm}$ and $50.51 \mathrm{~mm}$ respectively (Table 2) and the differences between male and female values were statistically significant $(\mathrm{P}=0.001)$. 
Table 1

Femoral head diameters in black Malawians

\begin{tabular}{|c|c|c|c|c|c|c|c|c|}
\hline \multirow[b]{3}{*}{ Parameter } & & \multicolumn{4}{|c|}{ Vertical diameter } & \multicolumn{3}{|c|}{ Transverse diameter } \\
\hline & & \multicolumn{2}{|c|}{ Right } & \multicolumn{2}{|l|}{ Left } & Right & \multicolumn{2}{|r|}{ Left } \\
\hline & & Male & Female & Male & Female & Male $\quad$ Fem & Male & Female \\
\hline $\mathrm{N}$ & 260 & 236 & 260 & 236 & 260 & 236 & 260 & 236 \\
\hline Range (mm) & $37.00-56.00$ & $39.50-53.00$ & $42.00-54.00$ & $38.00-56.00$ & $41.00-56.00$ & $40.00-57.00$ & $44.00-56.50$ & $40.00-55.00$ \\
\hline Mean (mm) & $48.30+$ & 44.61 & $48.30++$ & 44.50 & $50.36+$ & 46.54 & $50.75++$ & 46.50 \\
\hline $\mathrm{SD}(\mathrm{mm})$ & 3.51 & 3.44 & 3.11 & 3.42 & 3.62 & 3.72 & 3.02 & 3.28 \\
\hline $\mathrm{IP}(\mathrm{mm})$ & 53.00 & 37.00 & 56.00 & 42.00 & 57.00 & 41.00 & 55.00 & 44.00 \\
\hline Identified $\%$ & 10.50 & 01.80 & 00.00 & 17.20 & 00.00 & 08.00 & 09.40 & 27.60 \\
\hline $\mathrm{DP}(\mathrm{mm})$ & 54.93 & 37.77 & 54.76 & 38.95 & 57.64 & 39.40 & 56.34 & 41.69 \\
\hline Identified \% & 03.50 & 01.80 & 00.00 & 01.70 & 00.00 & 00.00 & 03.40 & 05.20 \\
\hline $\mathrm{SE}, \mathrm{mm}$ & 00.66 & 00.66 & 00.62 & 00.62 & 00.69 & 00.69 & 00.60 & 00.60 \\
\hline
\end{tabular}

$+\mathrm{P}=0.001$ vis means of the right female femurs, $++\mathrm{P}=0.001$ vis means of the left female femurs

$\mathrm{SD}=$ standard deviation; $\mathrm{SE}=$ standard error

Table 2

Comparison of the mean femoral diameters and identification points of femoral heads between Nigerians and Malawians.

\begin{tabular}{|c|c|c|c|c|c|c|}
\hline \multirow[b]{3}{*}{ Study } & \multicolumn{4}{|c|}{ Mean diameter (mm) } & \multicolumn{2}{|c|}{ Identification points $(\mathrm{mm})$} \\
\hline & \multicolumn{2}{|c|}{ Vertical } & \multicolumn{2}{|c|}{ Transverse } & \multirow[b]{2}{*}{ Male } & \multirow[b]{2}{*}{ Female } \\
\hline & Male & Female & Male & Female & & \\
\hline Southeast (Nigeria) (Singh et al. 1986) & 52.02 & 46.80 & 54.16 & 48.33 & 52.00 & 45.70 \\
\hline Southwest (Nigeria) Nwoha, 1990) & 50.35 & 47.04 & 50.75 & 45.55 & 55.00 & 45.00 \\
\hline Northeast (Nigeria) (Asala et al. 1998) & 54.16 & 47.00 & 49.90 & 43.09 & 51.50 & 42.30 \\
\hline Malawians (present study 1999) & 48.30 & 44.56 & 50.51 & 46.52 & 55.25 & 41.00 \\
\hline
\end{tabular}

Table 3

Comparison of the identification and demarking points of femoral heads between Nigerians and Malawians for sex determination

\begin{tabular}{|c|c|c|c|c|c|c|c|c|}
\hline \multirow{3}{*}{ Parameter } & \multicolumn{4}{|c|}{ Vertical femoral head diameter } & \multicolumn{4}{|c|}{ Transverse femoral head diameter } \\
\hline & \multicolumn{2}{|c|}{ Right } & \multicolumn{2}{|c|}{ Left } & \multicolumn{2}{|c|}{ Right } & \multicolumn{2}{|c|}{ Left } \\
\hline & Male & Female & Male & Female & Male & Female & Male & Female \\
\hline \multicolumn{9}{|l|}{ Present study } \\
\hline $\mathrm{IP}, \mathrm{mm}$ & 53.00 & 37.00 & 56.00 & 42.00 & 57.00 & 41.00 & 55.00 & 44.00 \\
\hline$\%$ identified & 10.50 & 01.80 & 00.00 & 17.20 & 00.00 & 08.00 & 09.40 & 27.60 \\
\hline $\mathrm{DP}, \mathrm{mm}$ & 54.93 & 37.77 & 54.76 & 38.95 & 57.64 & 39.40 & 56.34 & 41.69 \\
\hline$\%$ identified & 03.50 & 01.80 & 00.00 & 01.70 & 00.00 & 00.00 & 03.40 & 05.20 \\
\hline \multicolumn{9}{|c|}{ Southeastern Nigeria } \\
\hline IP, mm & 52.00 & 45.70 & 55.00 & 45.00 & 58.00 & 48.00 & 59.00 & 46.00 \\
\hline$\%$ identified & 45.00 & 27.50 & 17.00 & 27.50 & 12.00 & 37.50 & 10.00 & 18.80 \\
\hline $\mathrm{DP}, \mathrm{mm}$ & 55.60 & 42.21 & 56.59 & 41.42 & 57.67 & 44.41 & 58.00 & 43.57 \\
\hline$\%$ identified & 55.10 & 29.60 & 51.40 & 38.90 & 43.00 & 22.70 & 45.80 & 11.30 \\
\hline \multicolumn{9}{|c|}{ Northeastern Nigeria } \\
\hline $\mathrm{IP}, \mathrm{mm}$ & 53.20 & 44.70 & 53.50 & 44.30 & 50.10 & 40.80 & 49.40 & 39.40 \\
\hline$\%$ identified & 55.30 & 26.60 & 51.40 & 38.90 & 42.80 & 22.70 & 45.90 & 11.30 \\
\hline $\mathrm{DP}, \mathrm{mm}$ & 54.13 & 44.31 & 57.26 & 43.97 & 53.93 & 36.93 & 53.44 & 36.54 \\
\hline$\%$ identified & 29.20 & 24.70 & 30.70 & 25.10 & 39.30 & 00.00 & 38.10 & 00.00 \\
\hline
\end{tabular}

Note: IP = Identification point; DP = Demarking point 
Identification points (IPs): The male IPs derived from the vertical diameters were $53.00 \mathrm{~mm}$ for the right and $56.00 \mathrm{~mm}$ for the left femur. For females, the values were $37.00 \mathrm{~mm}$ and $42.00 \mathrm{~mm}$ for the right and left femur respectively (Table 1, Figure 2). Using the IP method, sex could be identified for $10.50 \%$ male right, $0.00 \%$ for male left, $1.80 \%$ female right and $17.20 \%$ female left. The IPs using the transverse diameters of the femoral head were $57.00 \mathrm{~mm}$ for male right, $55.00 \mathrm{~mm}$ for male left, 41.00 $\mathrm{mm}$ for female right and $44.00 \mathrm{~mm}$ for female left femur. From Table 1, Figure 2, IP successfully identified the sex of $0.00,9.40$ and $27.60 \%$ of femurs, respectively. More females than males were identified by both methods.

Demarking points (DPs): The DPs for males derived from vertical diameters were $54.93 \mathrm{~mm}$ right and 54.76 $\mathrm{mm}$ left. For females, the values were $37.77 \mathrm{~mm}$ right and $38.95 \mathrm{~mm}$ left. With the transverse diameters the values for males were $57.64 \mathrm{~mm}$ right and $56.34 \mathrm{~mm}$ left. For females the values were $39.40 \mathrm{~mm}$ right and $41.69 \mathrm{~mm}$ left. The percentage of bones identified by this method in both sexes was considerably less than the values recorded with IPs (Table 1 and Figure 2).

Tables 2 and 3 compare the mean femoral diameters and the identification and demarking points of femoral heads between Nigerians and black Malawians respectively.

\section{DISCUSSION}

Racial differences have been shown to exist in the dimensions of femoral heads from studies carried out by various authors $(1,3,6,8,14-17)$. Felts(18) believed that the gross shape of long bones was caused by intrinsic factors, while the specific details were determined by the bone adaptation to the functional environment. It is therefore likely that heredity is a major factor in the formation of the shape of long bones due to its different functions in different races. The average diameter of the head of the femur is therefore different in different races. Parsons(19) showed that if the vertical diameter of the head of the femur was greater than $48.00 \mathrm{~mm}$, the bone belonged to a male and when below $44.00 \mathrm{~mm}$, it indicated a female bone. For the Indian femora, Singh and Singh(1) reported figures of above $45.50 \mathrm{~mm}$ for a male bone and less than $41.50 \mathrm{~mm}$ for a female bone. Hasimoto(16) using the antero-posterior diameter for sex determination reported an average of $46.80 \mathrm{~mm}$ for Chinese femora. Studies in Nigerians $(3,8,14)$ used both diameters to determine sex employing identification and demarking points which was also employed in the present study.

The vertical and transverse femoral head diameters for males were significantly greater than the corresponding values for females $(\mathrm{P}=0.001)$. This is an indication that femora head diameters could be used for sex differentiation among black Malawians. The mean vertical and transverse diameters for Malawian males were less than the corresponding values for males in southeastern Nigeria
(Table 2). Similarly the mean vertical diameters for males and females in the present study were less than those of Nigerians studied (Table 2). Femoral head diameters may, therefore be of value in differentiating regional groups in Africa. Previous studies by Singh and Singh(1) and Asala et al (8) showed that these diameters could differentiate different groups in a particular country. The values of male right and left transverse and vertical diameters for Malawians, though greater than those of females, were, however, relatively lower than those of south-eastern(13) and south-western Nigerians(14) (Table 2). These differences could be explained on factors like diet, genetic and climatic conditions.

Both identification and demarking points for males were greater than those of females, an indication of the usefulness of these parameters in sex determination. It therefore follows that when femurs with intact heads are provided, sex can be assigned to them. This trend was also observed in the three studies carried out in the three regions of Nigeria $(3,8,14)$.

It was interesting to note that the values of male identification points for Malawians were similar to the values reported for Nigerians, but this was not the case with the female values when they were compared with their Nigerian counterparts (Table 3). It was also worth noting that fewer Malawians were identified into sex using identification points when compared to Nigerians (Table 3).

Using demarking points, lower percentages of bones of both sexes were identified than was possible when using identification points (Figure 2). This agrees with previous studies $(3,8,14)$. However, in contrast to previous studies, we were unable to identify more bones using both methods when compared to studies on Nigerian subjects (Table 3). This may be due to ethnic, linguistic, dietary and regional differences. Those bones, which were sexed using demarking points were however, of greater degree of certainty than those sexed by identification points. More females than males were identified by both methods due to the fact that the mean head diameter of male femurs fell within the range of diameters that did not permit positive identification of sex.

This study has shown that both methods exhibited sexual dimorphism, they were less sophisticated, require fewer measurements of femoral head diameters than current methods employed for sex determination. Besides, the use of DP method for sex determination gave a high level of accuracy. From these observations the authors of the present study recommend that in medico-legal cases where the more sophisticated and precise methods of sex determination of bones were lacking, IP and DP methods should be used. This is particularly true of African countries where forensic anthropologists are a rarity and anatomists are often called to determine the stature, sex and occasionally age of the skeletal remains of deceased persons. The present study, however, provides standard data for black Malawian subjects with the recommendation 
that similar standard values be established for other African countries within the region.

\section{ACKNOWLEDGEMENTS}

The authors are grateful to Ms T. Chirambo for her assistance in data collection and to Ms Sarah Butao of the Department of Anatomy, College of Medicine, University of Malawi for the secretarial assistance.

\section{REFERENCES}

1. Singh, S.P. and Singh, S. The sexing of adult femora: demarking points for Varanasi zone. Indian Med. Gaz. 1972; 11: 45-49.

2. Krogman, W.M. Skeleton in forensic medicine.Trans. Inst. Med. Chic. 1946; 16:1554-167.

3. Singh, S.P., Ekandem, G.J. and Ani, E.O. Identification of sex from the head of the femur: demarking points for Calabar, Cross-River state, Nigeria. West Afr. J. Anat. 1986; 1:16-23.

4. Stewart, T. D. Medicolegal aspects of the skeleton 1; age, sex, race and stature.Amer. J. Phy. Anthropol. 1948; 6: 315321.

5. Dwight, T. The size of the auricular surfaces of the long bones as characteristics of sex. An anthropological study. Amer. J. Anat. 1905; 4: 19-32.

6. Thieme, F.P. Sex in Negro skeleton. J. Forens. Med. 1957; 4: 72-81.

7. Javadekar, B.S. A study of the measurement of the head of the femur with special reference to sex. A preliminary report. J. Anat. Soc. India. 1961; 10: 25-27.
8. Asala, S.A., Mbajiorgu, F.E. and Papandro, B.A. A comparative study of femoral head diameter and sex differentiation in Nigerians. Acta Anatomica. 1998; 162: 232-237.

9. Luo, Y.C. Sex determination from the pubis by discriminant function analysis. Forens. Sci. Int. 1995; 74:89-98.

10. Introna, F.J., Di Vella, G. and Campobasso, C.P. Sex determination by discriminant analysis of patella measurements. Forens. Sci. Int. 1998; 95:39-45.

11. Hsiao, T.H., Chang, H.P. and Liu, K.M. Sex determination by discriminant function analysis of lateral radiographic cephalometry. J. Forens. Sci. 1996; 41:792-795.

12. Steyn, M. and Iscan, M.Y. Sex determination from the femur and tibia in South African whites. Forens. Sci. Int. 1997; 90:111-119.

13. Jit, I. and Singh, S. The sexing of adult clavicles. Indian Med. Res. 1966; 54:551-571.

14. Nwoha, P.U. Femoral head diameters in Nigerians. Afri. $J$. Med. Sci. 1990; 19:157 --161.

15. Iscan, M.Y. and Miller-Shaivitz, P. Sexual dimorphism in the femur and tibia. In: K. J. Reichs (Ed), Forensic Osteology: Advances in the detection of Human Remains, Charles C. Thomas, Springfield, ED 11. 1986; Pp. 102-111.

16. Hasimoto, M. Ethnologic studies on Chinese. J. Oriental Med. 1938; 29:32-34.

17. Lofgren, L. Some anthropometric anatomical measurements of the femur of Finns from the viewpoints of surgery. Acta Chinese Scand. 1956; 110: 479-484.

18. Felts, W.J.L. Transplantation studies of factors in skeletal organogenesis. Amer. J. Phy. Anthropol. 1959;17:201 - 215.

19. Parsons, F.G. The character of English thigh bone: the difficulty of sexing. J. Anat. 1914; 49: 335-361. 